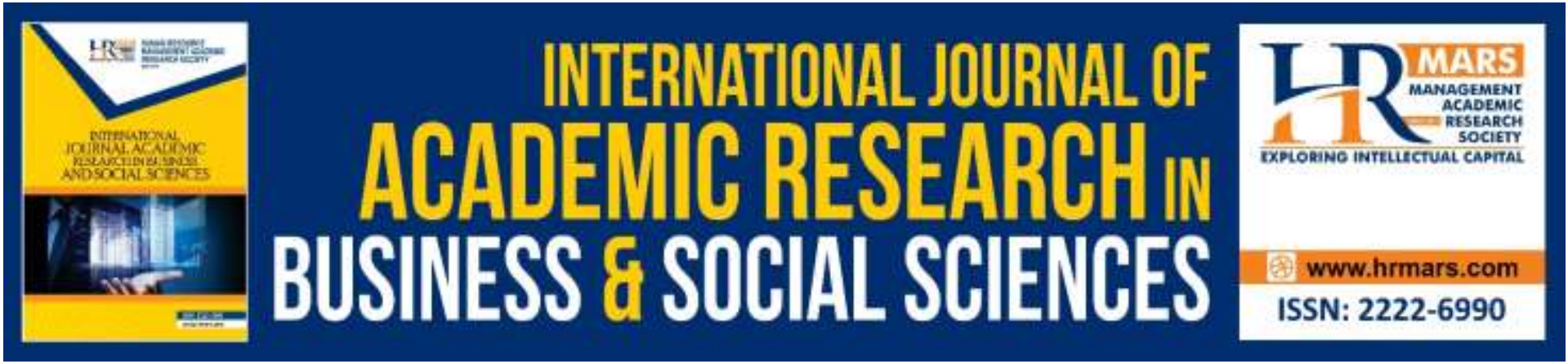

\title{
Malaysian Unity and Integration Aspiration: Enhancing Cultural Inclusiveness through Investigating Minority Group Identity Experiences
}

Noor Banu Mahadir, Zuraini Jamil@Osman, Nadarajan Thambu \& Tan Bee Piang

To Link this Article: http://dx.doi.org/10.6007/IJARBSS/v9-i10/6448

DOI: 10.6007/IJARBSS/v9-i10/6448

Received: 12 Sep 2019, Revised: 24 Sep 2019, Accepted: 03 Oct 2019

Published Online: 27 Oct 2019

In-Text Citation: (Mahadir, Jamil@Osman, Thambu, \& Piang, 2019)

To Cite this Article: Mahadir, N. B., Jamil@Osman, Z., Thambu, N., \& Piang, T. B. (2019). Malaysian Unity and Integration Aspiration: Enhancing Cultural Inclusiveness through Investigating Minority Group Identity Experiences. International Journal of Academic Research in Business and Social Sciences, 9(10), 51-66.

Copyright: (C) 2019 The Author(s)

Published by Human Resource Management Academic Research Society (www.hrmars.com)

This article is published under the Creative Commons Attribution (CC BY 4.0) license. Anyone may reproduce, distribute, translate and create derivative works of this article (for both commercial and non-commercial purposes), subject to full attribution to the original publication and authors. The full terms of this license may be seen at: http://creativecommons.org/licences/by/4.0/legalcode

\section{Vol. 9, No. 10, 2019, Pg. 51 - 66}




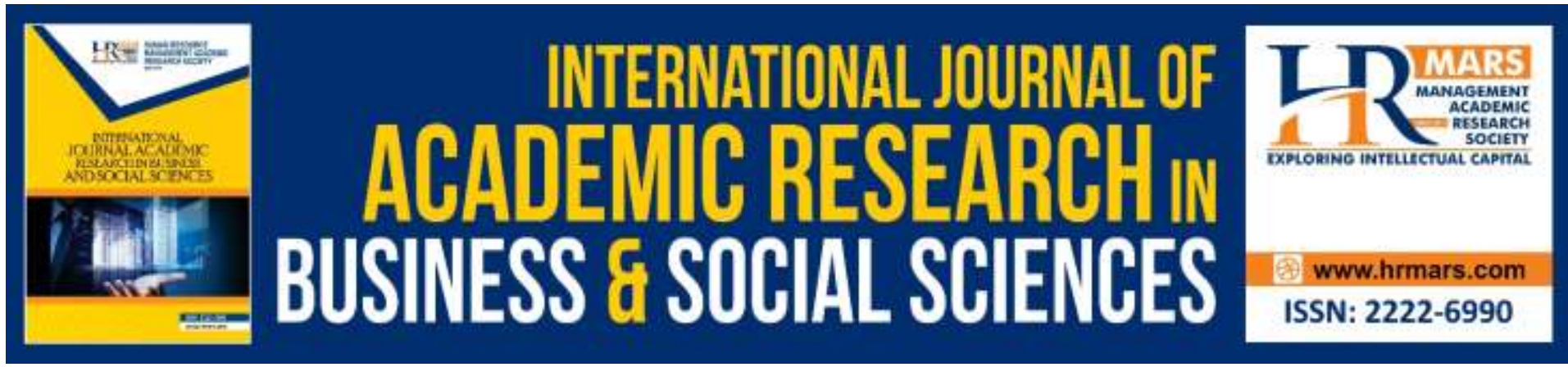

\title{
Malaysian Unity and Integration Aspiration: Enhancing Cultural Inclusiveness through Investigating Minority Group Identity Experiences
}

\author{
Noor Banu Mahadir, Zuraini Jamil@Osman, Nadarajan \\ Thambu \& Tan Bee Piang
}

Department of Moral, Civics and Character Building Studies, Faculty of Human Science, Sultan Idris Education University, Tanjong Malim, Perak, Malaysia

Email: noor.banu@fsk.upsi.edu.my

\begin{abstract}
Ethnic diversity has always posed a challenge to national identity and unity in plural societies. The quest of each ethnic group to maintain its culture, religion and language may lead to conflict with the central government's efforts at nation-building and integration. Given that Malaysia is an ethnically pluralist society, one of the major on-going tasks of the government has been to develop a nation which is harmonious, integrated and 'democratic' as a Malaysian nation. The nature of the current Malaysian national vision has been characterized as 'ethnically differentiated citizenship' that promotes Malay ness as a national identity whilst at the same time peripherally recognizing others' cultural identity. Education plays a role in achieving unity among students. It has been the aspiration and vision of Malaysia education proposes for unity and integration through education policy. Malaysia Educational Blueprint 2012-2025 has indicates that for diverse nations like Malaysia to embrace this diversity and prioritize social and systemic inclusiveness exhibit greater unity. Through interacting with individuals from a range of socio-economic, religious and ethnic backgrounds and learning to understand, accept and embrace differences a shared set of experiences and aspirations for Malaysia's future can be built. This research intends to explore the identity experiences of minority group in Malaysia using Yuval-Davis belonging framework. Identities experiences, such as how they perceived their cultural identity, how they perceived and negotiate with the national identity in their everyday interactions. In the spirit of ethnographic design, ten multiethnic student teachers (non-Malay Muslim group) at Sultan Idris Education University (SIEU) will be interview. Data gathering in this research includes focus group activity and in-depth interviews. The data will be analyze using a thematic analysis. The findings may reflect that minority 'everyday identity experiences' of multi-ethnic Malaysian marked comprehensive discourse of identity in Malaysia.
\end{abstract}

Keywords: Identity, Unity Aspiration, Multi-Ethnic Malaysia, Integration, Inclusiveness 


\section{Introduction}

Ethnic diversity has always posed a challenge to national identity and unity in plural societies. The quest of each ethnic group to maintain its culture, religion and language may lead to conflict with the central government's efforts at nation-building and integration. Given that Malaysia is an ethnically pluralist society, one of the major on-going tasks of the government has been to develop a nation which is harmonious, integrated and 'democratic' and which shares a national identity and values as a Malaysian nation. This aim has been a concern of the government from the day of independence right up to the present. The diversity of culture, religion and language, especially when any of these variables is used to provide special privileges to some groups and deny others equal opportunities to participate, may create ethnic inequality and ethnic polarization, leading to contentions, instability and upheaval. The nature of the current Malaysian national vision has been characterized as an 'ethnic-national hyphenated identity' and as 'ethnically differentiated citizenship'. The practiced of 'ethnically differentiated citizenship' in Malaysia promotes Malay ness as a national identity whilst at the same time peripherally recognizing others' cultural identity. Under the Malaysian constitution with regard to issues of citizenship, Article 153 entitles citizenship to non-Malays and in return grants Malays special rights in the fields of education, public services and commerce (Constitution, 2006). Tensions among ethnic groups may also result from national issues such as the distribution of economic wealth and social services, and from decisions regarding the national and official languages, political supremacy and cultural interests.

The notion of Malaysian differentiated citizenship has nevertheless proposed the questions of identity and belonging of the minority group in Malaysia. Do they conform with or dissent to the Malaysian nation vision identity that promotes the Malay ness identity. This research in particular explores how minority group student teachers articulated their identity experiences within Malaysian national vision citizenship. At times, the authority defined national identity conflicted with everyday defined or everyday identity experiences of multiethnic Malaysian. This research intends to explore the identity experiences of minority group in Malaysia using Yuval-Davis belonging framework (Yuval-Davis, 2011a). Identities experiences, such as how they perceived their cultural identity, how they perceived and negotiate with the national identity in their everyday interactions.

In the spirit of ethnographic design, ten multi-ethnic student teachers (non-Malay Muslim group) at Sultan Idris Education University (SIEU) were interview. Data gathering in this research includes focus group activity and in-depth interviews. The data were analyzed using a thematic analysis (Braun \& Clarke, 2006). The findings reflects that minority 'everyday identity experiences' of multi-ethnic Malaysian marked comprehensive discourse of identity in Malaysia. Student teachers experiences of identity may conform with and sometimes dissent to the 'authority defined' identity (Malaysian nation vision identity framework). In one hand, they may have clear understandings of national identity in 'Malaysian way' that pointed of Malayness identity and therefore it could be suggested that minority identity experiences have both inclusionary and exclusionary implications.

\section{Methodology}

A paradigm that underpin a research consists of the following components: ontology, epistemology, methodology and methods. Epistemology is concerned with the nature and forms of knowledge (Cohen, Manion \& Morrison, 2000). Epistemological assumptions are 
concerned with how knowledge can be created, acquired and communicated. In other words, epistemology is what it means to know. Ontological assumptions are concerned with what constitutes reality. In other words, ontology refers to what is (Scotland, 2012). Different paradigms hold differing ontological and epistemological views; thus, they have differing assumptions of reality and knowledge which underpin their particular research approach. This is reflected in their methodology and methods. Methodology is the strategy or plan of action that lies behind the choice and use of particular methods (Crotty, as cited in Scotland, 2012).

The understandings of identity and citizenship in multi-ethnic society with regard to the literature on both Malaysian and Western the two preceding chapters, researchers explained their understanding of the key themes that underpin identity and citizenship theories and their related issues within the field of citizenship. These understandings in turn informed the nature of the research questions raised, an indication that this research falls within the constructivist research paradigm. The details, understandings, values and beliefs of the minority group of teachers in terms of everyday identity experiences were reached by following a research string of constructionism, interpretative and qualitative. The decisions and justifications behind selecting this approach are discussed in detail in the following sections.

\section{Research Approach and Design: Interpretative Approach and Qualitative Research}

The interpretive paradigm is concerned with understanding the world as it is from the subjective experiences of individuals. They use meaning-based (versus numerical measurement-based) methodologies that focus on participant observation and interviewing and which rely on a subjective relationship between the researcher and subjects.

In this particular study, the minority group student teachers' everyday experience narratives, as an instrument of identity construction, were framed by the particular interview encounter. It unfolded as a process of meaning-making, weaving together experiences and events in a particular gestalt, or overall construction of reality.

This study aimed to obtain information of a socio-cultural nature about Malaysia and in particular the minority group student teachers' identity experiences in multi-ethnic Malaysians. Becoming a part of the experiences of these young people, and observing their struggles and challenges, researchers felt more confident that they had established clear insights into the lived worlds of these participants, an idea which is at the heart of qualitative work. Another characteristic of this study was the use of multiple methods in order to develop the 'story' as experienced by the multi-ethnic student teachers. The use of qualitative research tools in this study: observation, focus group activity and in-depth interviews as the main instruments, and also short-term fieldwork at sites, justify why this study is seen not as a traditional ethnography but instead as a focused ethnography design. The focus groups and in-depth interviews were complemented by ethnographic accounts of the student teachers' service-learning sites, namely the university and service-learning placement sites, through participant observation, informal interviews and documentary evidence. The application of focused ethnographic design as my research approach was particularly appropriate, given the nature of my aim and research questions. 
This study did not intend to test any hypothesis but it relied on what can be inferred from its subjects and an understanding of the student teachers' citizenship and identity understandings, values and beliefs by adopting an induction process. In other words, it was assumed that by probing the participants' accounts of actions, it would help to understand how they experienced identity and citizenship in multi-ethnic Malaysia. As the interpretative perspective is characterized by the subjectivity of knowledge, the researcher was actively involved with the participants through various methods of data collection in order to understand belonging, identity and citizenship and citizenship from the perspectives and experiences of the student teachers. Thus, the researcher did not isolate himself from the investigated context; rather, the researcher was the main data-collecting instrument and was the active contractor of the meanings (Radnor, 2002). The purpose of this research is to investigate minority group student teachers' identity experiences in multi-ethnic Malaysia. The purpose is not to test a hypothesis, prove a theory or to gather statistical evidence but to explore minority group beliefs, values and attitudes on identity. Using a qualitative approach best serves the research purpose. It focus on the production of objective and reproducible data but is concerned with meaning, and how it informs subjective understanding (Banister, 2011; Hollway \& Jefferson, 2000).

In depth interviews and focus group interviews of ten multi ethnic minority group student teachers consists of one Chinese, one Indian, three Kadazan-Dusun, three Iban and two orang Asli ethnicity group who enrolled into moral education program in Sultan Idris Education University (SIEU). The student teachers' everyday experienced narratives, as an instrument of identity construction, were framed by the particular interview encounter. It unfolded as a process of meaning-making, weaving together experiences and events in a particular gestalt, or overall construction of, reality.

The student teachers who involved in this research were sampled on the basis that they showed some features of interest for the research purpose and questions raised. Therefore, the participants were purposively sampled (Silverman, 2013).

There were two types of interviews in this study, the focus group and in-depth interviews. The researchers conducted a focus group interviews that aimed at building rapport between the researcher and the researched. Through this first focus group, the researcher have an opportunity to get familiarized with the participants, their personal background, the communities they lived in and their experiences of inter-ethnic relations. The focus group interview also provided preliminary insights into the identity experience. The data from the focus group interview highlighted that the multi-ethnic student teachers had experienced living in a multi-ethnic society and showed what they knew and how they experienced tolerance and recognition. In-depth interviews will be conduct to capture comprehensive and detailed responses on identity experience that are expressed in different stories, values and in the feelings experienced by the student teachers. The framework of belonging and Malaysian nation vision below will be the main frame in this research. 


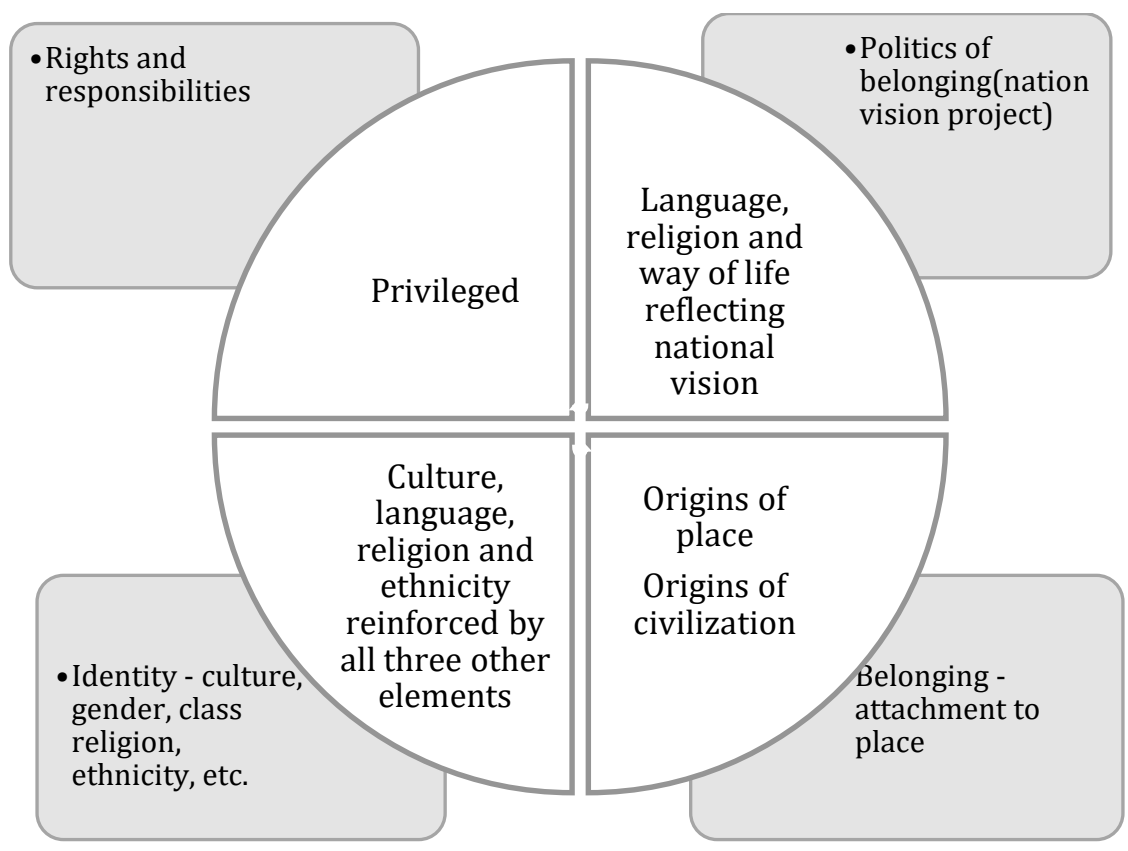

Diagram 1: Belonging and Politics of Belonging Framework

In her belonging and the politics of belonging framework, Yuval-Davis (2006) defines belonging as a dynamic process concerning emotional and ontological attachments' (p. 197), while the politics of belonging comprises specific political projects aimed at constructing belonging to particular collectivities. She differentiates three levels: social locations, identifications and emotional attachments, and ethical and political values. The first facet of social locations concerns the varying positionalities such as ethnicity, nationality, age and class which shape people's sense of belonging; the second she comprehends as individuals' identifications and emotional attachments to various collectivities and groupings, and the last is closely associated with the politics of belonging. Yuval-Davis argues that these different levels are interrelated, but cannot be reduced to each other, as so many political projects of belonging tend to assume (p. 196-203).

In presenting the findings, the minority group were characterized according to their legal status that confer them with certain privileges under the Malaysia constitution. They are the peripheral privileged group and unprivileged group. The peripheral privileged group are the non-Malay bumiputera and the unprivileged group are the Chinese and Indian whilst the Malay group are characterized as a privileged group.

\section{Findings}

In this research, researcher has looked at two key areas that relates to minority identity within Malaysia differentiated citizenship that are identity and belonging. The belonging and politics of belonging by Yuval-Davis is used Yuval-Davis' dimension of belonging that concerns attachment on emotional and ontological levels (Yuval-Davis, 2011a, p. 10) and the politics of belonging that encompass specific political projects aimed at constructing belonging to particular collectivities. The student teachers' identity experiences were constructed along multiple axes of difference, such as ethnic, culture, region, age and class. On the one hand, these social locations were stable and they promoted a sense of belonging 
but, on the other hand, they came with power relations and differentials between the majority and minority groups, creating a context requiring negotiation and challenges (YuvalDavis, 2011b).

In relation to belonging, it is found that student teachers' conceptualized their ethnic identity as a cultural representation of who they were. Student teachers felt the emotional attachment to the nation within their collective groups through cultural and language sameness. Narratives within the politics of belonging dimension on the other hand showed how student teachers positioned their identity in terms of the 'other' that had less recognition in terms of cultural and special rights compared to the core privileged group. Malaysian ethnic preferential citizenship has created two blocs of identities: majority and minority identities, or dominant and subaltern. In particular, the students believed that Malaysia's ethnic preferential citizenship has led to a politically constructed identity that is divided between privileged and unprivileged groups and which reinforces differences rather than unity.

The national identity within the belonging dimension showed the importance of national identity in multi-ethnic Malaysia as an integration mechanism and support for the plurality of multi-ethnic Malaysia. For example, having a national language can evoke a sense of commonality, of 'Malaysian-ness' (one Malaysia) and generate emotional attachment to being part of a multi-ethnic community. However, the differences in rights and privileges could at times lead to a boundary between the majority and minority group, between them and us.

In conclusion, the student teachers' identity experiences of social attachment and a feeling of belonging suggests these student teachers feel they have achieved minimal recognition in relation to their cultural identity and fundamental membership rights. The student teachers' everyday identity and membership experiences showed inclusive and exclusive forms of belonging where they experienced 'superficial recognition'. They talked about cultural disrespect, unequal economic distribution, their voices going unheard and even humiliation through negative identification.

According to Antonsich (2010), studies on multiculturalism confirmed if people feel that they can express their identity and been recognized as part of the community, they can feel belonging to the community. Ameli \& Merali (2004) also pointed out that, to be belong to the community, one should be valued and listened to. Nevertheless, in this research, to some extent the experiences of identity and belonging within the Malaysian national vision framework have at times left the minority group feeling less valued and less belongingness to the nation.

In this study, belonging is evoked in association with identity, national identity and citizenship rights and responsibilities (Yuval-Davis, 2004). Yuval-Davis, referring to the communitarian understanding of citizenship as a way of belonging to a community, suggests that:

Belonging is not just about membership, rights, and duties . . . nor can it be reduced to identities and identifications, which are about individual and collective narratives of self and other, presentation and labelling, myths of origin and destiny. Belonging is a deep emotional need of people. (p. 215) 


\section{Identity and Belonging}

The first dimension of (Yuval-Davis, 2004), belonging is identity narratives and belonging as personal, intimate feelings that promote a sense of belongingness to the cultural group as well as to imagined communities. For some minority student teachers', their ethnic identification preferences aim to represent their socio-cultural identities as part of multiethnic Malaysia. Student teachers' identity narratives suggested they felt emotional attachment to their cultural sameness (language, ritual activities and tribal events), but their sense of self and attachment to place was also strongly reinforced by the authority-defined elements of the framework. Ethnicity and identity were particularly important for this unprivileged group as part of their everyday-defined reality, but although authority-defined reality was supported by them, it was not necessarily seen as holistically reinforcing their sense of citizenship.

For minority student teachers' who were members of the Eastern Malaysian indigenous group, they wanted to be known by their tribe, language and cultural group identity. The Eastern Malaysian indigenous group (native people in Eastern Malaysia) associated their identity with geographical, socio-cultural and linguistic positioning. These people may have adopted a particular community name to distinguish themselves from others, yet they were still conscious of kinship with other communities. Kinship, language, customs, physical characteristics, behavior and so on played a part in determining the degree of relationship that one community shared with another.

Some Eastern Malaysian student teachers preferred to be associated with the specific cultures of their tribe or ways of being in a tribal group; Eddy spoke about the Iban indigenous group as his ethnic identification:

we are not just indigenous but more specifically, we are the Iban indigenous group.... who were known as head-hunters. We have our own language and culture. (Eddy, male, Iban ethnic group)

Caleb spoke of the positive identities of his cultural group:

I perceived myself as [one of the] Bidayuh indigenous group from Borneo. People should know that the indigenous Bidayuh is soft spoken and polite people. (Caleb, male, Bidayuh ethnic group)

For other Eastern Malaysian student teachers, ethnic identity was seen as an important part of being Malaysian. Due to their different historical backgrounds, the Eastern peoples have been seen by the Malays as a new group of Malaysians. They belong to a more heterogeneous cultural group compared to the Western Malaysian cultural group. Nevertheless, since the Eastern Malaysian region has been given less attention by the Federal States situated in West Malaysia, not all Western Malaysians know about the multi-ethnic indigenous societies in Eastern Malaysia (Andaya \& Andaya, 2001).

For the unprivileged group (Chinese and Indian student teachers') perceived their identity as culturally represented by a hybrid identity of, for example, Malaysian -Chinese and Malaysian-Indian. The Chinese student teachers, for example, wanted others to acknowledge the existence of 'Malaysian-Chinese' - people of Chinese descent that no longer live on Chinese soil but are still considered to be ethnically Chinese. The hyphenated identities of 'Malaysian-Chinese' or 'Malaysian-Indian' represent two aspects of identity: one part derived from their ethnicity and the other part derived from being a member of the Malaysian nation. 
They wanted to be known as 'Malaysian-Chinese' or 'Malaysian-Indians', to differentiate them from Chinese from China, or Indians from India, but yet still held on to the culture and language of their ancestral lands as an important part of their ethnicity. Such a hybrid identity can be dynamic and flexible or more fixed depending on the individual, but certainly involves negotiation on a sense of self and belonging. In some cases, this involved adherence to a Malaysian identity whilst also retaining aspects of being Chinese (Lee, 2009).

Alex Tan and Sundari stressed that they were Malaysian and should no longer be seen as descendants of immigrants. Their loyalty is to Malaysia and not their ancestral homeland. They want others to accept them as Malaysian citizens. Nevertheless, it has been argued that Malaysian-Chinese still generally maintain their distinctive 'core' Chinese accents, diets, mannerisms and lifestyles, in addition to speaking their respective Chinese dialects (Lam \& Yeoh, 2004, , p. 146). Alex Tan illustrates:

I am Malaysian-Chinese, Chinese because this is my ethnic identification; I want people to know that I am Chinese because of my culture and heritage; I speak Mandarin; I embrace Buddhism and Confucianism as my way of life.

I am Malaysian because this is my new homeland and to differ my identity from Chinese from China. (Alex Tan, Malaysian-Chinese, male)

Most of the peripheral and unprivileged student teachers had similar understandings of their cultural identities as members of a particular grouping within a multi-ethnic Malaysia. They wanted to be known as part Malaysian with differences of culture, language and identities. I related these identity narratives as ethnic belonging, which implies emotional attachment associated with feelings of cultural belongingness. Nevertheless, ethnic identity as selfidentification or identification by others is always a dynamic process and not a reified fixity. Identity narratives can shift and change and can be contested and multiple.

However, ethnic identity can be a political project that promotes the maintenance of boundaries between 'them' and 'us'. The peripheral and unprivileged student teachers sometimes perceived their identity as lacking in status - they belonged to a minority group with fewer privileges and had to negotiate their ethnic identity in their everyday relationships with the core privileged group. They had to accept that their language and religion were less acknowledged and recognized. They believed they were seen as the minority who were obliged to respect the core privileged group identity. Sometimes, they felt that ways of being Chinese, Indian or aboriginal were not fully understood and thus they believed that they received less recognition and respect from the majority.

For example, some student teachers explained that they experienced cultural intolerance in their everyday inter-ethnic interactions with members of the core privileged group. They spoke of superficial respect and tolerance among inter-ethnic relations in Malaysia. Tom, a student teacher in Eastern Malaysia, expressed his dissatisfaction with the core privileged group's treatment of others. He shared his inter-ethnic experiences with members of the core privileged group, who he felt disrespected other cultures.

'they' the Malays always undervalue other cultures; They 'the Malays' placed their status of dominant and privileged group gave them exclusive power. They see us as an additional group and they told us what we should do or should not do. They told us not to have a cultural event in student accommodation; they told us to respect 
them as Malays and Muslims, what about us, do we have voice here? (Tom, Eastern Malaysian indigenous, male)

Tom's experiences indicated that, for him, the Malays maintained boundaries between themselves and others. They (Malays) demanded respect and recognition in their everyday interaction with the PPG. Tom also expressed his dissatisfaction with what he felt was disrespect by the core privileged group towards cultural events.

Some of the student teachers spoke of 'ethnic stereotyping' in their everyday interactions with the core privileged group. Mee Da commented on how people looked down on her aboriginal identity in her everyday interactions.

people look down on us, the aborigines. They laugh at us. They say aborigines (peoples) are dirty, poor, (belong to) a different class of society, at the pit, at the bottom... The say we (are) uncivilized people, they have to tell us what to do, how to be civilized. (Mee Da, aborigine, female)

MeeDa's narrative suggests that non-Malay groups are sometimes denied respect as human beings. (Honneth, 1992) form of recognition, the second basic form of recognition, is achieved through the acknowledgement of one's formal capacity for autonomous moral action. He proposed forms of disrespect where one can experience disrespect when individuals or collective lifestyles face designations as 'insult' or 'degradation' (Honneth, 1992). It could be said that Mee Da experienced forms of disrespect when her ways of being an aborigine were insulted. Sandy shared her 'religion misrecognition' narrative where one of the Eastern Malaysian indigenous cultural events was not fully recognized.

although we have been given the freedom of religion, (but) there are certain cultural events that were not well understood by the majority. I am referring to the Gawai Festival; it is a big ritual event for us as important as Eid for the Malay Muslims but the semester calendar has never put it as an important date; it is only a day off and those of us who lives far from home face a difficult time to go back home and celebrate the event with our family. (Sandy, Eastern indigenous, female)

The second area of belonging that emerged in this analysis was national identity. In the contextual analysis chapter, I mentioned that national identity in Malaysia was making the core privileged group identity a common identity while giving minimal recognition to the cultural symbols of other ethnic groups. The Malay language, Islam and Malay culture were the key elements to representing Malaysian national identity.

Although it was clear that national identity is a 'political' project that implied belonging as a discursive resource which constructs, claims, justifies or resists forms of socio-spatial inclusion or exclusion, I nevertheless suggest that national identity could also promote place belongingness to imagined communities. I argued in chapter 1 that the Malaysian government has tried to develop a nation which is harmonious, integrated and 'democratic' and one which shares a sense of a unified national identity and values. This aim has been a concern of the government from the time it achieved independence until today, and this is reflected in the need to develop a united Malaysian nation. Nevertheless, to unite a multi- 
ethnic society is not an easy task. There have been hurdles and challenges along the way. The lack of an understanding of diversity and Malaysian history may have contributed to misunderstandings, cultural misrecognition and so on.

The premise of inclusion and citizenship belongs to a single polity, nation and culture, however, living in a multicultural nation state raises questions about the nature of this belonging (Bond, 2006). It has been argued that the claim to national belonging of those characterised by 'difference' (not least with respect to national and ethnic origins) may be problematic because of beliefs held by the majority and their judgements of the validity of such claims. In general, these student teachers conformed to Malay notions of there being a coherent national identity in Malaysia. Student teachers' acceptance was in line with the government's nation-building project that aimed to integrate multi-ethnic societies through one common identity. For Tom, national identity represents a nation where one belongs:

national identity is very important to represent a nation. We are a multi-ethnic society that means we have different cultures, languages and religions. There is no other way to unite us except we have a common identity. I would (be) very happy to say that I am (a) Malaysian who speaks the Malay language. (Tom, Eastern indigenous, male)

Some student teachers took a more flexible stance when responding to Malay elements as a national identity. They responded to opportunities to preserve their own culture and identity as a 'delicate balance' between Malaysia's collective national identity and ethnic community identity. Malaysia's collective national identity is drawn from the 'constitutional bargains agreement' (Cheah, 2002) that recognises historical immigrants' legitimate interests (rights in economy), rights to citizenship and residence as well as their freedom to preserve, practice and propagate their religion, culture and language. In the above 'exchange', Malays retained the major symbols of 'their' nation, that is, their king, their special position, their language (Malay as the official language) and their religion (Islam as a state religion) (Ibrahim, 2004). The subaltern student teachers' everyday experiences of national identity reflected their understandings of the Malaysian constitutional bargains. The Federal Constitution had proposed terms and compromises among the various racial components of Malaysian society that embodied inter-communal consensus on the character of the national polity and the respective rights, privileges and obligations of the various ethnic communities. In return for grants of citizenship to the ethnic Chinese and Indian immigrant communities, the Malays received special economic privileges flowing from their status as bumiputera or indigenous 'sons of the soil' as well as special language rights, and Islam was designated as the religion of the federation in Article 3 of the Federal Constitution. Some student teachers spoke about the opportunity given to them to preserve their own culture whilst at the same time claiming a place within the nation. Mee $\mathrm{Da}$, a peripheral privileged student teacher, illustrated this point:

national identity represents who we are as Malaysians and we still can preserve our cultural identity, the state still endorses the rights of all Malaysians to express and share their cultural heritage, their language and religion. National identity is about our belonging to a Malaysian nation. (Mee Da, aborigine, female)

For some student teachers, national identity has been perceived as a tool of integration in line with the need for a national identity, as set out in the government's national policies, to 
develop a united Malaysian nation. They spoke in particular about the Malay language as an opportunity to unite multi-ethnic Malaysians. For them, it is difficult to achieve unity on religious or ethnic grounds, but language can transcend the ethnic and religious differences and create bonds across ethnic lines that will provide the means for a sense of national identity (Gill, 2014). Peripheral and unprivileged student teachers were very fluent in the national Malay language and they believed it united them.

Warith illustrated this point:

Malay language has not just been used to communicate with CPG Malays but also with PPG and UPG. For Malaysians, the Malay language, which is the national and official language, is a primary outward sign of a group identity. The Malay language acts as an integrating device between the people of Western and Eastern Malaysia. (Warith, Thais, male)

Alex Tan also commented

I think the Malay language has achieved integration; some of the multi-ethnic people in Malaysia, especially in the village where I can see Chinese, Indian and Malay old folks, communicate in the Malay language. We use the Malay language to communicate with the Malays and also with each other. (Alex Tan, Malaysian-Chinese, male)

In summary, within the belonging dimension, the student teachers articulated national identity as a sense of national belonging to the Malaysian nation. They felt proud to be Malaysians. They believed that the use of the national language in their everyday inter-ethnic communication contributed to the integration of multi-ethnic Malaysians. The use of the Malay language as a unifying language could also narrow the ethnic gap between the privileged group and the subaltern group due to the fact that every pupil from different ethnic backgrounds uses Malay as a formal and informal communication tool. In a broader sense, this is an important aspect of national integration, a central part of state policy as the country faces a complex social pattern with a population which is multi-ethnic in nature and separated by the different ethnic groups with their own cultures, languages, identities and values. It has been accepted that education is expected to play a significant role in nurturing national consciousness, moulding national identity and forging national unity amongst the various ethnic groups in Malaysia (Jamil \& Raman, 2012).

\section{Multi-Ethnic Belonging: Respect, Recognition and Tolerance}

In this analysis, the notion of belonging also includes student teachers' identity negotiation in their everyday inter-ethnic relations. For Carens (2000), the question of belonging in diverse societies needs to address differences to accommodate diverse cultural, ethnic and national groups. They proposed a distinctive model of citizenship that sought to recognize multiple forms of belonging to the political community and overlapping identities and citizenships by addressing the minorities' differences and acknowledging them. They proposed adding the protection of minority groups' cultural rights from discrimination and the safeguarding of minority groups' cultural identities (Carens, 2000).

Minority group of student teachers accepted and adapted to the national identity in their everyday relations with the core privileged group. They highlighted their recognition of 
Malay culture and the legitimate ownership of Malaysia by the Malays. Eddy spoke of the historical rights of the Malays as the 'owners' of the country who deserved their privileged rights. Eddy referred to the Malays as the historical owners of Malaysia. By historical owners he meant those who fought for Malaya's independence, those who came first to Peninsular Malaysia and established a civilised community during the flourishing of the Malay Archipelago kingdom.

honestly speaking, I don't feel distressed with the core privileged group's special privileges. They deserve it, this is their country and they fought for independence. I think they still accommodate others' cultures and rights. I can still enjoy my cultural rights. (Eddy, Indigenous, male)

Eddy's comments indicate his recognition of the Malays as the dominant group and as the original people of Malaysia and he also expressed his satisfaction with the Malaysian way of citizenship that still accommodates other cultures and ethnicities.

Some student teachers responded positively to the core privileged group's ethnoreligious identity. They articulated their recognition through respect of the Malay Muslim ways of life and they have to respect this particular difference. The student teachers showed their respect for the Muslim ways of life. They were aware of the special nature of the Muslim diet, Muslim girls' dress code and Muslim prayers. Most peripheral and unprivileged student teachers had mixed with Malay Muslims since their school years. It was clear that the nonMalay Muslim student teachers conformed to the core privileged group's special rights by showing their respect for the Malay Muslim ways of life. They accepted the fact that the majority of Malaysians were Muslims and they had very specific ways of life. It could be said that the peripheral and unprivileged group accepted their subordinate position and willingly recognised and respected the dominant group. They took the stance that, being part of multiethnic Malaysia, they should respect the constitution and build good relationships with the dominant group. They accepted the constitutionally defined position of the dominant group and their privileges.

However, using Yuval-Davis' (2002) politics of belonging dimension, the national vision led by the government can be seen as a political project that has attempted to unify but which has also created boundaries between 'them and us'. Some student teachers said that their everyday experiences of identity conflicted with their understandings of the national vision. Some student teachers believed that the national vision was about 'fitting in' in order to be accepted by the majority political and social communities. In terms of national language, they believed that they enrolled into the national school system and learnt the national language as this gave them the opportunity to be accepted by public universities. A pass in the Malay language is necessary to be awarded the national higher certificate and in order to enrol in a public university. Fluency in the Malay language is also a prerequisite for public service employment opportunities. Speaking Malay was therefore seen as a way of bringing people together through a common language, but was also used to enforce compliance as the Malay language has become an essential language for any career progression. 
Some student teachers commented on the 'national dress code', the bajuMelayu or traditional costume of the Malay community which is also the country's national costume and is to be worn for all official functions (Koh \& Ho, 2009). Some of the peripheral and unprivileged student teachers believed that wearing Malay dress (bajukurungorbajuMelayu)in school or during national events at times reflected how some of them felt that they had to 'fit in' in order to be accepted by the dominant group.

Here (at Sultan Idris Education University), we have to follow certain dress code, for example during official events, we sometimes are encouraged to wear bajukurung (Malay attire). We sometimes felt wearing this made the Malay feel comfortable with us. They felt we respect them as the dominant group. Sometimes we think we follow the dress code to fit in with the dominant group. (Tom, indigenous, male)

Some non-Malay Muslim student teachers spoke of how the politics of national identity in Malaysia promotes Malay ways of life for the Malay and also for the non-Malay. As an example, Malay traditional dress (national dress) should be worn at official events. Therefore, non-Malays sometimes feel that they have less opportunity to embrace or demonstrate their own culture, such as their traditional dress or any of their cultural events. They felt their own cultures were not given an opportunity for recognition. The student teachers believed that having a national identity synonymous with Malay identity was a necessary part of the integration and unity sought by the government. Nevertheless, there were times when their everyday experiences in relation to national identity conflicted with their own cultural identities and these hindered their sense of belonging in terms of fitting in. The Malaysian preferential policies had reinforced the core privileged group's ethnic identity and ways of being Malay and Muslim, which led to a sense of a highly promoted idea of Malay supremacy. At the core of this mindset, of the Malay supremacy proponents, was the belief that Malaya belonged to the Malay people, it was a Malay polity and had remained principally so despite colonialism and its subsequent independence. Therefore, it was argued that this provided ideological justification to argue that non-Malays, with their non-native ancestral origins, should not expect equal treatment in terms of political entitlement and status. Comprehensive implementation of the ethnic-based preferential policies and national policies were translated progressively into institutional entrenchment of Malay political primacy justified on the basis of indigeneity(Ting, 2009).

\section{Conclusion}

In sum, it could be said that minority group narratives of cultural and ethnic identity have promoted place belonging to their cultural group and within the politics of belonging (national vision project), they have been minimal rights accorded to preserve their own cultural identity. National policies (politics of belonging) may have proposed an identity of Malayness, but they have also permitted others to practice their own ways of being. Chinese ethnic groups in Malaysia, for example, are allowed to practice their own culture and ways of being Chinese. Indian ethnic groups in Malaysia are allowed to send their children to a Tamil type of school. Malaysian television and radio channels allow Tamil, Mandarin, Kadazan and Iban (Borneo) stations on air every day. Daily newspapers in different languages are also allowed. 
In relation to national identity, since independence, the efforts of the government to integrate multi-ethnic Malaysia have been considered to be successful. The Malay language has been used as a national language at every level - urban and rural, formally and informally, officially and unofficially. National identity within the belonging dimension showed the importance of national identity in multi-ethnic Malaysia as an integration mechanism and support for the plurality of multi-ethnic Malaysia. For example, having a national language can trigger a sense of commonality, of 'Malaysian-ness' and generate emotional attachment to being part of a multi-ethnic community. However, the differences in rights and privileges could at times lead to a boundary between the majority and minority group, between them and us. Identity discourse of minority group created tension when they interacted with the core privileged group in their everyday inter-ethnic relations. They have to negotiate, to fit in with the mainstream. They sometimes felt uncomfortable, less recognized and less respected.

\section{Contribution}

This research has contributed to the theoretical knowledge of the identity, citizenship and belonging field in several ways; the research has contributed to the discourse on identity and belonging in three different ways. Firstly, in terms of the literature on citizenship, identity and belonging discourse in Malaysia, it has provided a more detailed insight into how citizenship and identity in Malaysia can be discussed from both the authority-defined and everydaydefined realities. The study has shown how minority group identity was conceptualized, what it means or should mean and the values attributed to ways of belonging to a Malaysian nation. Within this research, the language of citizenship in everyday experiences conflicted with authority-defined citizenship, setting up dissonance and dissatisfaction. These challenges and negotiations are insights that can support and explain some of the outcomes of previous research where they have reported a lack of readiness and/or rejection of the idea of an inclusive, multi-ethnic society (Baumeister, 2003). More importantly, this research has provided examples that have pointed out specific areas that need to be addressed in terms of possible inequities and the prejudices which can inhibit the building of a cohesive society.

\section{Acknowledgements}

This research was undertaken with the assistance of a University Research Grant (GPU 20170133-106-01). The authors wish to express their gratitude to Sultan Idris Education University for providing the research funds, as well as the parties involved in this research.

\section{References}

Ameli, S. R., \& Merali, A. (2004). British Muslims' Expectations of Government (Vol. 2). Islamic Human Rights Commission London.

Andaya, B. W., \& Andaya, L. Y. (2001). A history of Malaysia. University of Hawaii Press.

Antonsich, M. (2010). Searching for belonging-an analytical framework. Geography Compass, 4(6), 644-659.

Banister, P. (2011). Qualitative methods in psychology: A research guide. McGraw-Hill Education (UK).

Baumeister, A. (2003). Ways of Belonging Ethnonational Minorities and Models ofDifferentiated Citizenship'. Ethnicities, 3(3), 393-416.

Bond, R. (2006). Belonging and becoming: National identity and exclusion. Sociology, 40(4), 609-626. 
Braun, V., \& Clarke, V. (2006). Using thematic analysis in psychology. Qualitative Research in Psychology, 3(2), 77-101.

Carens, J. H. (2000). Culture, citizenship, and community: A contextual exploration of justice as evenhandedness. Oxford University Press.

Cheah, B. K. (2002). Malaysia: the making of a nation (Vol. 1). Institute of Southeast Asian Studies.

Constitution, F. (2006). Laws of Malaysia. Reprint Federal Constitution Incorporating All Amendments Up To, 1.

Gill, S. K. (2014). Language, Nation-Building and Identity Formation in a Multi-Ethnic Society. In Language Policy Challenges in Multi-Ethnic Malaysia (pp. 17-33). Springer.

Hollway, W., \& Jefferson, T. (2000). Doing qualitative research differently: Free association, narrative and the interview method. Sage.

Honneth, A. (1992). Integrity and Disrespect: Principles of a Conception of Morality Based on the Theory of Recognition. Political Theory, 20(2), 187-201. Retrieved from http://www.jstor.org/stable/192001

Ibrahim, Z. (2004). Globalization and national identity: Managing ethnicity and cultural pluralism in Malaysia.

Jamil, H., \& Raman, S. R. (2012). Malaysian educational policy for national integration: Contested terrain of multiple aspirations in a multicultural nation. Journal of Language and Culture Vol, 3(1), 20-31.

Koh, J., \& Ho, S. (2009). Culture and customs of Singapore and Malaysia. ABC-CLIO.

Lam, T., \& Yeoh, B. S. A. (2004). Negotiating 'home'and 'national identity': Chinese-Malaysian transmigrants in Singapore. Asia Pacific Viewpoint, 45(2), 141-164.

Lee, Y. F. (2009). Everyday identities in Malaysian Chinese's subjectivities. Akademika, 75, 2141.

Silverman, D. (2013). Doing qualitative research: A practical handbook. SAGE Publications Limited.

Taylor, C. (1994). The politics of recognition. Multiculturalism: Examining the Politics of Recognition, 25, 25.

Ting, H. (2009). The politics of national identity in West Malaysia: Continued mutation or critical transition? Southeast Asian Studies, 47, 31-51.

Yuval-Davis, N. (2004). Borders, boundaries, and the politics of belonging. Ethnicity, Nationalism, and Minority Rights, 214.

Yuval-Davis, N. (2011a). Power, intersectionality and the politics of belonging.

Yuval-Davis, N. (2011b). The politics of belonging: Intersectional contestations. Sage. 